Published as Brown, S.D. 2015. Health in the experience ecology. Psicologia della Salute 18(1): 36-41. DOI: 10.3280/PDS2015-001004

\title{
Health in the experience ecology
}

Steven D. Brown

University of Leicester

Rose Capdevila's work is a fine example of how 'critical' approaches to health and social psychology have matured in the past two decades. As befitting a scholar whose self-described interests are around 'the production of inclusion and exclusion; sameness and difference', the work discussed here demonstrates a commitment to theoretical and methodological pluralism, whilst maintaining a strong connection to fundamental question of agency, choice and experience. If there was the possibility, for a while perhaps, of critical psychologist turning themselves into philosophers or sociologists in their efforts to break from mechanistic images of the psychological subject, then what we see in the work of Capdevila and her colleagues is a return to what defines psychology as a discipline: the task of making sense of who and what we are across the manifold, intersecting contexts in which we dwell.

Making such a return is not easy - not least because of the fatigue that has set in with the rhetoric of scholarly 'turns'. Early psychology (i.e. that of the midnineteenth century) looked to the progress being made in physiology and chemistry for the intellectual and practical tools to wrest questions of human experience away from idealist philosophy. Measurement and experimentation were essential resources here for producing a dynamic image of humans as living organisms engaged with their environment. However, over time, the 'experiments and variables' approach that was initially so productive became rather less so. As Capdevila notes in relation to the 'biopsychosocial model', parceling up the complexities of health into discrete bundles of variables tends to over-inflate the role of the individual as the causal locus. Indeed it is salutary to note the extent to which our still formative understanding of the brain and genetics has led to a re-engagement between the clinical sciences and philosophy (as seen in the work of Antonio Damasio, Steven Rose, Catherine Malabou and many others). And where medicine goes, psychology can be sure to follow.

The other obstacle has been that of the idea of the 'rational actor'. Here the key disciplinary relationship is between psychology and economics. Clearly the shift from seeing behaviour as controlled by the environment to being the output of a rational calculation of probabilities on the part of the person was immensely significant. Consider, for example, how the early applications of game theory and cybernetic models transformed psychology between 1950-1975. But even during this period, several key figures saw the limitations of such modeling. Gregory Bateson, for instance, noted that 'the mental world - the mind - the world of information processing - is not limited by the skin' (1973: 429). Treating information processing as a rational, brain bound activity offers as limited a perspective on the relationship between humans and their environments as the purely behaviorist view, and may in fact be possibly worse in some cases. We see 
Published as Brown, S.D. 2015. Health in the experience ecology. Psicologia della Salute 18(1): 36-41. DOI: 10.3280/PDS2015-001004

this realization gradually dawning on economists, as they have begun to abandon rational choice models in favour of 'behavioral economics', which have - in the UK at least - begun to work their way into social policy with the aim of creating environmental 'nudges' towards 'healthy' or 'productive' behaviours. Here Capdevila's finding that MMR immunization 'choices' are treated by mothers as matters of compliance is an interesting reflection on just how far this kind of thinking has travelled with regard to the contemporary governance of social welfare.

There is in all of this a real danger that the ground which psychology has carved out in relation to philosophy, medicine and economics will be ceded once these disciplines no longer need the version of 'mind' to which psychologists default (i.e. the brain-bound rational standard cognitive model). So what is the alternative? In her paper, Capdevila identifies many of the key elements that will be required. The most important is an emphasis on practices. Associated with 'psychosocial' and 'sociocultural' approaches, the term practice denotes the organization of cognition and emotion in structured activities that bear the mark of both culture and power. For example, the mothers in the MMR study treat immunization decisions within the framework of what it is culturally to be a 'good mother' in their local contexts. Within the practice of 'good motherhood', immunization is just something that one does, because it demonstrates engagement with wider discourses of social responsibility. Although note that, as Capdevila observes, the timing of the study may be relevant here. What 'counts as' being responsible changes over time, in accordance with social and cultural definitions. We have to think of the social as composed of a tangled web of practices, connected together through variable multiple relays of knowledge and power rather than as a static set of personal, social and economic variables.

Although Capdevila shys away from using the terms, cognition and mind can be situated with respect to practices once they are treated as distributed across settings. As long ago as 1934, John Dewey was arguing that 'mind' ought to be treated as referring to shared activities embedded social domains:

For in its non-technical use, 'mind' denotes every mode and variety of interest in, and concern for, things: practical, intellectual and emotional. It never denotes anything self-contained, isolated from the world of persons and things, but is always used with respect to situations, events, objects, persons and groups ... Mind is primarily a verb. It denotes all the ways in which we deal consciously and expressly with the situations in which we find ourselves. (Dewey 1934: 274-5)

Dewey argues here that 'technical' (i.e. formal-theoretical) conceptions of mind have lost touch with what they are attempting to explain, namely the myriad ways in which persons are involved and concerned with one another and the world around. Dewey's argument belongs to a body of work from the early twentieth century, including that of William James, Alfred North Whitehead and Henri Bergson, that called for psychological investigations to be re-founded on a notion of the fundamentally distributed and collective nature of human activities and capacities (see Brown \& Stenner, 2009 for more on this). Despite the intermittent efforts of psychologists such as Kurt Lewin or JJ Gibson, it has taken 
Published as Brown, S.D. 2015. Health in the experience ecology. Psicologia della Salute 18(1): 36-41. DOI: 10.3280/PDS2015-001004

some time for that call to be properly answered through the recent emergence of 'distributed', 'enactive' and 'embodied' approaches to cognition. Although there are significant differences within these approaches as to where to discern the 'mark of the cognitive', we can say that our capacity to engage with matters of choice and agency is afforded by the features and resources of the settings in which these activities are enacted. Thus, many of Capdevila's participants would most likely be unable to arrive at a defensible 'decision' to immunize or not because the technical resources that would be required to frame the activity (i.e. knowledge of spread of disease across populations; ability to conduct probabilistic outcomes of different clinical outcomes) are just not available in the settings they inhabit.

The move towards a distributed approach to cognition has gone some way towards restoring the place of embodiment in psychological analysis. As critical scholars of health have been arguing for some time, we do not just have bodies, we are embodied beings who relate to the world corporeally and affectively as well as mentally. In a post-dualist framework, thinking is a material and embodied matter. However it is important to differentiate this concern with embodiment from the rather misguided effort at reducing psychology to the study of brain states. In this respect, Capdevila's identification of the diverse ways in which mothers describe their bodies postpartum makes clear that the very different local contexts and specific relationships around motherhood shape how bodies are experienced. Similar biological states give rise to many different kinds of experiences depending on the 'relationships in circulation around an issue', as Capdevila puts it. The lived body is infinitely more plastic in terms of its experiential and relational affordances than a purely biomedical reading would suggest.

We can see the central importance here of experience. This is a deceptively simple term that seems to denote an involvement in ongoing life events. In Capdevila's text it is sometimes used as an adjunct to 'meaning' or 'understandings', as with the phrase 'participants experiences'. Experience might be glossed here as 'the things that happen to us' which become the subject matter for the stories and narratives we tell. It is in this sense, I think, that Capdevila offers her very useful observation that health professionals might seek to offer 'alternate viable narratives' that 'can provide mothers with new ways of understanding their own experiences'. Narrative frameworks, constructed out of local cultural understandings, can scaffold a given experiences in different ways, with implications for how persons relate to and manage their embodied states.

Whilst I am in complete agreement with this practical recommendation, there is something analytically which still needs to be teased out around experience. To begin with we can note that it is difficult to establish a clear categorization of particular sets of experiences. If 'the same thing' gives rise to multiple understandings, then perhaps part of the problem is this initial attribution of 'sameness' to the experience. This move is relatively easy to make if we expand the geographical or historical framing of experience - clearly the birthing and postpartum experiences of Capdevila's participants differ markedly from mothers in contemporary rural Uganda or Victorian London. But even within the same cultural or historical setting, loosely defined, becoming a mother can be 
Published as Brown, S.D. 2015. Health in the experience ecology. Psicologia della Salute 18(1): 36-41. DOI: 10.3280/PDS2015-001004

such a radically diverse experience for different women and families that it demands further analytic differentiation. Moreover, for all of us, experience is by definition not a matter of a passage between distinct states. Experience involves tonal shifts in affect and understanding, along with corporeal feelings and sensations, such that that any given time we are somewhere in-between one specific experience and another. Whitehead suggested a notion of an ongoing, perpetual transition (or as Gilles Deleuze puts it 'continuous variation') better captured the fleeting nature of experience:

Nothing can be omitted, experience drunk and experience sober, experience sleeping and experience waking, experience drowsy and experience wide-awake, experience self-conscious and experience selfforgetful, experience intellectual and experience physical, experience religious and experience sceptical, experience anxious and experience care-free, experience anticipatory and experience retrospective, experience happy and experience grieving, experience dominated by emotion and experience under self-restraint, experience in the light and experience in the dark, experience normal and experience abnormal (Whitehead, 1935: 291)

All well and good philosophically, perhaps, but how can this approach to experience be realized in empirical terms? I think the answer comes through extending the approach that Capdevila takes to cultural understandings. Capdevila's application of Q-methodology, for instance, involves the assumption that there is a discursive ecology around a given topic, where multiple discourses and narratives are in play that can be empirically recovered through the factor analytic procedure. But there is also an experience ecology in which participants are embedded. To echo Whitehead we might say that there are 'easy' and 'difficult' births. 'Good' and 'bad' wards and hospitals. 'Excited' and 'terrified' parents. 'Energised' and 'traumatised' bodies. 'Supportive' and 'rejecting' families. 'Helpful' and 'obstructive' professionals. 'Fulfilled' and 'miserable' lives. And everything in-between... Postpartum body image emerges from this rich, shifting mosaic of experiences.

Situating a particular kind of health relevant life event (such as becoming a mother) within an experience ecology encourages us to focus on the varieties of possible experiences that may be in play. But it also directs attention to ways in which experience can be canalized and transformed through power relations. By way of example, Bateson's well-known ethnography of Balinese culture emphasizes the particular qualities of child-parent relationships. Bateson argued that whilst it is possible to imagine a range of potential trajectories to childparent relationships, based on notions of dependency, nurturing, lineage etc, amongst the Balinese there is a strong 'ludic' framework where parents 'tease' and 'provoke' children. This framework was derived from a more general model of conflict and conflict-resolution in Balinese culture, Bateson claimed, where interpersonal disputes are managed by heightening tensions until they reach a point of maximum intensity (or 'plateau') followed by immediate resolution. This cultural practice had then been overlaid on child-parent relations, giving them their particular experiential tones. 
In the case of either becoming a mother or making immunization decisions, we can note that social and cultural practices take hold of the diversity of an experience ecology and subject it to particular pressures. For example, 'best practice' around birth and after-care in the UK National Health Service sets a powerful agenda in which mothers and partners are encouraged to relate to one another and their child in very specific way. To extend the ecological metaphor a little further, whilst there are diverse experiences of birthing, the way hospitals and community based health professionals work tends to channel those experiences in quite specific ways. So whilst experience is, by definition, diverse, fluid and changeable, the management of health care creates 'chreods' or pathways, based on relations of power and knowledge, which exert a tendency toward homogenization. We might conclude that it is not just different narratives that are needed here, but also different 'ecological practices' with respect to motherhood.

This leads us towards what I think is one Capdevila's most important points. As psychologists, we need to be reflexively aware of how our knowledge practices shape the experiences of those who engage with them. Along with colleagues, I have used the phrase 'psychologically modified experiences' (PMEs) to describe this process (see Brown et al, 2014). We developed the term to help us clarify what appeared to be happening around patient sexuality on a secure forensic psychiatric unit. Many patients on the unit described their sense of themselves as a sexual being as having been transformed in negative ways during their time on the unit. One patient referred to this as 'amputated sexuality' - a sense of being actively distanced from sexuality, of having been required to leave sexual desires and feelings in the past. It became apparent to us that this transformation in experience was a direct result of the ways that patient sexuality was oriented to and managed by staff on this unit, and that this in turn was a systemic feature of how professional psychological discourses of 'risk', 'vulnerability' and 'predation' were being operationalised in secure forensic psychiatric care.

The term 'psychologically modified experience' is meant to echo that of 'genetically modified organism' (GMO). From an existing ecology, a particular quality is extracted that is then subject to modification by a knowledge practice, before being returned to that ecology where it becomes the dominant 'strain'. 'Amputated sexuality' is a PME that is created by taking the diversity of patient sexuality, subjecting it to discourses and practices that emphasise the dangers of so-called 'vulnerable' persons engaging in sexual feelings or acts, and then ensuring that it is the only 'appropriate' form in which sexuality can be expressed. In the same way that GMOs 'push out' other crop strains or biological species, so the danger here is that health practices which foster PMEs may wreak havoc on the 'experience ecologies' on which they are overlaid. It is with work such as Capdevila's, with its careful attention to the role of psychology in 'shaping the objects of which is speaks' (to paraphrase Foucault), that we may perhaps find the beginnings of a more 'sustainable' way for psychologists and health professionals to act. 
Published as Brown, S.D. 2015. Health in the experience ecology. Psicologia della Salute 18(1): 36-41. DOI: 10.3280/PDS2015-001004

\section{References:}

Bateson, G. 1973. Steps towards an ecology of mind. New York: Peregrine. Brown, S.D. \& P. Stenner 2009. Psychology Without Foundations: History, Philosophy and Psychosocial Theory. London: Sage.

Brown, S.D., P. Reavey, A. Kanyeredzi and R. Batty 2014. Transformations of self and sexuality: psychiatric inpatients accounts of sexuality and relationships. Health 18: 240-260.

Dewey, J. 1934. Art as Experience. New York: Perigree.

Whitehead, A. N. 1935. Adventures of Ideas. Cambridge University Press: London. 